2013-02

\title{
Pesticide consumption and productivity and the potential of IPM in Bangladesh
}

\author{
Rahman, Sanzidur
}

http://hdl.handle.net/10026.1/4001

10.1016/j.scitotenv.2012.12.032

Science of The Total Environment

Elsevier BV

All content in PEARL is protected by copyright law. Author manuscripts are made available in accordance with publisher policies. Please cite only the published version using the details provided on the item record or document. In the absence of an open licence (e.g. Creative Commons), permissions for further reuse of content should be sought from the publisher or author. 


\title{
PESTICIDE CONSUMPTION AND PRODUCTIVITY AND THE POTENTIAL OF IPM \\ IN BANGLADESH
}

\section{Sanzidur Rahman}

\begin{abstract}
The paper analyses trends in consumption, productivity and the determinants of pesticide use in Bangladesh over a 33 year period (1977-2009) including a discussion on the scope to expand Integrated Pest Management (IPM) practices. Pesticide use grew at an alarming rate of $10.0 \%$ per year $(p<0.01)$ although corresponding response in yield growth of major crops has been minimal $(<1.0 \%$ per year). Pesticide productivity (i.e., 'gross value added from crops at constant prices' per ' $\mathrm{kg}$ of active ingredients of all pesticides used') is declining steadily at a rate of $-8.6 \%$ per year $(p<0.01)$. Adoption of green revolution technology, crop diversification, average farm size and literacy rate are the significant determinants of pesticide use whereas $R \& D$ investment depresses pesticide use. Consistent evidence of excessive pesticide use in Bangladesh was observed. Although the government has shifted focus from pesticide use to IPM, its coverage remains inadequate as only $7.4 \%$ of the total farmers are covered after 30 years of effort. Tighter pesticide regulation and its effective implementation, and expansion of IPM through public, private and NGO stakeholders are suggested to reduce pesticide consumption.
\end{abstract}

KEY WORDS: Pesticide consumption and productivity, determinants of pesticide use, Integrated Pest Management (IPM), Bangladesh.

\section{Introduction}

Farmers use a wide range of pesticides to prevent crop losses from pest attack thereby improving yield as well as quality of the produce. Pesticide can also improve nutritional value of food and 
sometimes its safety and its use can be viewed as an economic, labour-saving and efficient tool for pest management (Damalas and Eleftherohorinos, 2011). There has been a continuous growth of pesticide usage both in numbers and quantities since the 1940s. For example, total pesticide production has increased from one million metric ton (mmt) in 1965 to nearly $6 \mathrm{mmt}$ in 2005 (Carvalho, 2006). Emergence of pest resistance to pesticides is one of the major negative aspects of pesticide use, compounded by a widespread claim that the chemicals employed are harmful to human health and the environment (Hou and Lu, 2010; Pimentel, 2005; Pingali, 1995; Antle and Pingali, 1994). The environmental and social impact of pesticide use in the USA alone is estimated at USD10 billion per year (Pimentel, 2005). An estimated 1-5 million farm workers suffer from pesticide poisoning every year and at least 20,000 die annually from exposure, mostly in developing countries (World Bank.org, undated). Pesticide poisoning is more widespread in developing countries compared to developed countries (Hou and $\mathrm{Lu}, 2010$ ). There is also widespread acceptance that the expansion of modern agricultural technologies has led to a sharp increase in pesticide use (Pingali and Rola, 1995). However, despite growing evidence of the social, health and environmental cost of pesticide use, farmers in developing countries will continue to use pesticides due to: (a) an ignorance of the sustainability of pesticide use; (b) a lack of alternatives to pesticides; (c) an underestimation of the cost of pesticide use both in the shortand the long-run; and (d) the weak enforcement of laws and regulations governing pesticide use (Wilson and Tisdell, 2001).

Pesticide use in Bangladesh, negligible until the 1960s, has recorded a dramatic increase over the past four decades. This is partly due to government's preference to adopt chemical control measures to increase crop production as well as to prevent pre- and post-harvest crop losses (Aziz, 2005; Matin, 2003; Rahman, et al., 1995). However, a rapid increase in pesticide 
consumption raises concern about its potential impact on farmers' health as well as on the environment. Studies on pesticide use in Bangladesh are relatively limited, although news/magazines often report widespread use of banned pesticides including incidences of pesticide poisoning (e.g., IRIN, 2010). Furthermore, systematic information on the level and scale of pesticide use over time and pesticide management practices of the government is largely non-existent. Except a couple of papers on pesticide use in Bangladesh covering the period 1973-1995 (i.e., Matin, 2003; Rahman et al., 1995), most of the remaining studies are based on farm surveys that dealt with determinants of pesticide use at the farm-level at a point of time (e.g., Dasgupta et al., 2005; Mahmoud and Shively, 2004; Rahman 2003, Rahman and Hossain, 2003, and Hossain et al, 1999).

Given this backdrop, the present study attempts to provide a comprehensive analysis of the pesticide use scenario in Bangladesh over time. Specifically the study: (a) examines trends in the consumption and productivity of pesticide use and identify its determinants over a 33 year period (1977-2009) at the national level; (b) presents a discussion on pesticide management practices (i.e., government policies, regulations, ban status); and finally (c) examines the scope to expand Integrated Pest Management (IPM) practices to control pests.

\section{Methodology}

\subsection{Sources of data}

Information on pesticide use in Bangladesh is very limited which partly explains relative lack of research on the topic. The present study is based on the analysis of available secondary data on pesticide use, as well as a review of existing literature dealing with pesticide issues in Bangladesh. The primary sources of quantitative information are the various issues of Statistical 
Yearbooks of Bangladesh published annually by the Bangladesh Bureau of Statistics (BBS, various issues from 1977 to 2010); Handbook of Agricultural Statistics 2007, a compendium volume covering national level information on key agricultural indicators from 1972-2006 (BBSa, 2009), Agricultural Census reports of 1983/84; 1996 and 2008 (BBSb, various issues); Bangladesh Population Censuses of 1981, 1991, 2001 and 2011 (BBSc, various issues); Annual/Revised Annual Development Reports of the Planning Commission 1977 to 2010 (PC, various issues) and reports from government agencies (e.g., DOE, 2005; MOA, 2002), publications that are available either internationally or nationally (e.g., Dasgupta et al., 2005; Rahman and Hossain, 2004, Rahman, 2003), and news and reports that are backed with research findings and are widely available at the international public domain (e.g., Katalyst, 2010; IRIN, 2010). When data comes from separate censuses, data for the inter-census years were constructed using a standard linear trend interpolation model.

\section{$2.2 \quad$ Pesticide productivity}

Productivity in economics is defined as the ratio of output to input.

$$
\text { Productivity }(P)=\frac{\text { Output }}{\text { Input }}=\frac{Q}{X}
$$

Since information on pesticide use in specific crop is not available, we define pesticide productivity as a ratio of 'gross value added from all crops measured at 1984/85 constant prices' to 'active ingredient of all pesticides used'. Since output index is measured at constant prices, changes in the output index reflect actual changes in the physical quantities of crops produced over time. Therefore, Eq (2) effectively measures the level of aggregate output that a unit of 
active ingredient of pesticide produces over time (i.e., $\mathrm{BDT}^{\mathbf{1}} / \mathrm{kg}$ ), which is a partial measure of productivity as other production inputs (e.g., fertilizers, labour, seeds, etc.) are not included.

\footnotetext{
${ }^{1}$ BDT stands for Bangladeshi Taka. Exchange rate 1 USD = BDT 25.96 in 1985 and BDT 85.00 in 2011.
} 


\subsection{Trend analysis}

Average annual compound growth rates were estimated using semi-logarithm trend functions by applying Ordinary Least Squares (OLS) procedure. The model is specified as follows:

$\ln Y=\alpha+\beta T$

where $Y$ is the target variable whose trend is to be estimated, $T$ is time, ln is natural logarithm, and $\beta$ is the parameter that measures the average annual compound growth rate. The null hypothesis that 'the estimated growth rate is zero $\left(\mathrm{H}_{0}: \beta=0\right)$ ' is tested in every case to determine the statistical significance of either positive or negative growth rate of the variable of interest.

\subsection{Determinants of pesticide use}

A host of factors may be responsible for pesticide use over time at the macro level, such as, use of modern technologies, changes in cropping diversity, changes in average farm size, etc. In order to identify the factors explaining use of pesticides over time, we have specified a pesticide determination function (dropping the $t$ subscript for time) as follows:

$\ln P=\alpha_{1}+\gamma \ln G R+\sum_{k=1}^{5} \beta_{k} \ln X_{k}+\varepsilon$

where, $P=$ amount of active ingredients of pesticide used per hectare of Gross Cropped Area $(\mathrm{GCA})(\mathrm{kg} / \mathrm{ha}) ; \mathrm{GR}=$ Green Revolution (GR) technology adoption rate (i.e., proportion of High Yielding Varieties (HYV) of rice area grown in all three seasons, i.e., Aus, Aman and Boro, in GCA), $X_{1}=$ Herfindahl index of crop diversification (a measure of concentration defined as $D_{H}=\sum \delta_{j}^{2}, 0 \leq D_{H} \leq 1$, where $\delta_{\mathrm{j}}=$ area share occupied by the $j$ th crop $^{2}$ in $\left.G C A\right) ; X_{2}=\mathrm{R} \& \mathrm{D}$ investment in agriculture (million BDT at 1984/85 constant prices); $X_{3}=$ Extension expenditure

\footnotetext{
${ }^{2}$ We have analysed the changes in areas planted with eight major crop groups (aggregated from a total of 47 individual crops). The crop groups are (i) foodgrains, (ii) cash crops, (iii) pulses, (iv) oilseeds, (v) spices, (vi) potatoes, (vii) vegetables, and (viii) fruits.
} 
(million BDT at 1984/85 constant prices); $X_{4}=$ Average farm size (ha); and $X_{5}=$ Average literacy rate (proportion of literate adult population aged 7 years and above in total population); ln stands for natural logarithm; $\alpha, \beta, \gamma$ are the parameters to be estimated; and $\varepsilon$ is the error term.

However, it should be noted that the rate of GR technology adoption which enters as a regressor in Eq (3) also depends on a similar set of factors specified in Eq (3). Therefore, we also specify a GR technology adoption function:

$$
\ln G R=\alpha_{2}+\sum_{k=1}^{6} \gamma_{k} \ln X_{k}+\mu
$$

where $X_{6}=$ irrigation rate (proportion of modern irrigation area in GCA) which is a pre-requisite for GR technology adoption; $\mu$ is the error term. All other variables are defined earlier.

Choice of the variables in these models is based on existing literature. Also, most of these selected variables are either policy driven or amenable to policy changes. In order to account for the recursive nature and endogeneity of the specified models, we jointly estimate the system of equations (3) and (4) by applying the Three Stage Least Squares (3SLS) regression procedure. This system of two structural equations, thus specified, is identified and is, therefore, estimable ${ }^{3}$. STATA-V10 software is used to estimate all the models (STATA, 2007).

\footnotetext{
${ }^{3}$ In order to enable estimation of a linear system of equations, the necessary condition for identification of an individual structural equation is as follows: if $m_{i}>\left(K-k_{i}\right)$, then the equation is under-identified and cannot be estimated; where, $m_{i}$ is the number of endogenous variables in an individual structural equation; $k_{i}$ is the number of exogenous variables in the same structural equation; and $K$ is the total number of exogenous variables in the system (STATA, 2007). In this system of structural equations, the value of $m_{i}$ in pesticide model is one and the value of ( $K$ $\left.-k_{i}\right)$ is also one. In GR technology model there is no endogenous variable. Therefore, the identification condition is satisfied and the system as a whole is just-identified and can be estimated.
} 


\section{Trends in pesticide consumption, productivity and determinants}

\subsection{Principal pests of major crops in Bangladesh}

There are about 209 species of pests/mites of different crops and stored products (Table 1, for a full list of these pests, please see Das, 1998). Table 1 demonstrates that the farmers in Bangladesh face a formidable challenge to bring in their harvest without losing some or all the potential yield to pests and mites. Rice is the most important crop in Bangladesh occupying $78.3 \%$ of the gross cropped area in 2009 (BBS, 2010) and is prone to pest attacks almost every year. The principal pests of rice plants are the stem borers and plant hoppers and the most serious pests of rice and wheat in storage are the weevils, moths and beetles (Table 1; Rahman et al., 1995). There is no concrete evidence on the annual average area affected by pests. However, Teng et al., (1990) noted that crop loss by pests in Bangladesh ranges from $30-80 \%$ during pest outbreaks and 3-20\% during no outbreaks (cited in Hossain et al., 1999). Tea and jute, which are the principal export crops, are also affected by several types of pests (Table 1; Rahman et al., 1995).

\section{[Insert Table 1 here]}

\subsection{Trend in pesticide consumption}

Use of pesticides in crops is dependent upon pest infestations and the types of crops grown. Nevertheless, consumption of pesticides grew by a staggering $1,440 \%$ from only 3,135 metric tons of active ingredients in 1977 to 45,172 metric tons in 2009. Figure 1 and Table 2 present the growth indices and average annual compound growth rates of pesticides, fertilizers and major crop areas in Bangladesh during 1977-2009 using Eq. (2). It is clear that the consumption of pesticides closely followed growth in the area under HYV rice and wheat as well as consumption of the inorganic fertilizers. In fact, pesticide consumption grew more rapidly than that of 
inorganic fertilizers, the key input required to grow HYV rice.

[Insert Figure 1 and Table 2 here]

\subsection{Trend in the composition of pesticides}

The composition of pesticide over time is dominated by insecticides ranging from $72 \%$ to $98 \%$ of total pesticide use (Figure 2). Fungicides reached a peak of $28 \%$ of total pesticide use only in 1981 and flattened dramatically thereafter. However, the use of fungicides and herbicides has been increasing slowly in recent years. The main reasons for increased use of granular insecticides is ensured efficacy, a longer protection period, the scarcity of workable spray equipment, and 'ready to use' formulation (Matin, 2003). Although data do not exist on the chemical composition of pesticides, Rahman et al., (1995), examining pesticide use information for the year 1987/88, noted that organophosphates are the major types (60.4\%) followed by carbamates $(28.6 \%)$, organochlorines $(7.6 \%)$ and others $(3.4 \%)$. The farm level evidence also provides a similar picture. For example, Rahman (2003) reported that $69.4 \%$ of the 406 surveyed farmers surveyed in 1997 used organophosphates followed by carbamates $(19.2 \%)$, organochlorines (6.8\%) and pyrethroids (4.6\%) in 1996.

\section{[Insert Figure 2 here]}

\subsection{Trend in pesticide use rates}

Although pesticides were rarely applied to crops in the past, the consumption of pesticides increased substantially following the diffusion of GR technologies in Bangladesh. Pesticide usage also became an essential component for other non-cereal crops as well. Correlation analysis on the data presented in Figure 1 revealed that pesticide use is almost perfectly correlated with fertilizer use $(r=0.96, p<0.01)$ as well as area under HYV rice $(r=0.96, p<0.01)$, vegetables $(\mathrm{r}=0.98, \mathrm{p}<0.01)$, and fruits $(\mathrm{r}=0.93, \mathrm{p}<0.01)$. Farm-level evidence from Bangladesh 
also suggests similar conclusions. For example, pesticide use is significantly influenced by area under traditional and HYV rice, potatoes, spices, vegetables and cotton (Rahman, 2003), vegetables and cereals (Rahman and Hossain, 2003) and the degree of vegetable commercialization (Hossain et al., 1999), respectively. Not only has the total consumption of pesticides increased as shown in Figure 1, but also the use rates of pesticides has increased by $1,103 \%$ from only $0.26 \mathrm{~kg}$ of active ingredient per ha of GCA area in 1977 to $3.13 \mathrm{~kg} / \mathrm{ha}$ in 2009 . The current figure is substantially higher than India estimated at $0.57 \mathrm{~kg} / \mathrm{ha}$ (Raghu et al., 2003) and Vietnam at $0.30-0.50 \mathrm{~kg} / \mathrm{ha}$ for rice and $0.50-1.00 \mathrm{~kg} / \mathrm{ha}$ for vegetables (Nhan, 2003) but far lower than Japan at $12.00 \mathrm{~kg} / \mathrm{ha}$ (Bami, 1996, cited in Raghu et al., 2003).

Figure 3 presents the growth indices and Table 2 presents the growth rates of the use of pesticides and fertilizers per ha of GCA and the yield of major crops per ha. It is clear from Figure 3 that, although the use rates of pesticides and fertilizers per ha are spiralling upwards, the yield rates of major crops are almost static. The implication is that the increased use rates of pesticides per ha did not result in increasing yield levels of major crops. For example, the yield of HYV rice, wheat, pulses, potatoes and oilseeds grew at a rate of less than $1 \%$ per year, while pesticide use rate per ha of GCA grew at an astonishing $10.0 \%(\mathrm{p}<0.01)$ per year over the 33 year period under study. Rahman (2010) attributed the reasons for poor yield of HYV rice to the use of lower than recommended doses of fertilizers (by up to 40-70 per cent), expansion to less suitable lands and depletion of soil fertility. The poor growth in yield of non-cereals is attributed to the fact that modern technology is only well established in potatoes and two-thirds of the 131 HYV non-cereals, developed by Bangladesh Agricultural Research Institute, were released only from 2006 (Rahman, 2009), whose impact on yield growth at the farm-level is yet to be seen as the dissemination of the technology from research stations to farms is very slow in Bangladesh. 


\section{[Insert Figure 3 here]}

\subsection{Trend in pesticide productivity}

Figure 4 presents the trend in pesticide productivity using Eq (2). It is clear from Figure 4 that although pesticide productivity increased during the first few years of application, the overall trend is negative. Pesticide productivity is estimated at BDT 35,243.2 per $\mathrm{kg}$ of active ingredients in 1977 declining to BDT 4,556.8 per $\mathrm{kg}$ in 2009. The average annual growth rate is estimated at $-8.6 \%(\mathrm{p}<0.01)$. The case of fertilizer productivity is similar, which is also declining at an average annual rate of $-4.2 \%(\mathrm{p}<0.01)($ Table 2$)$.

\section{[Insert Figure 4 here]}

During the initial years, domestic demand for pesticides was almost exclusively catered for by imports which later declined steadily and currently only a third of total pesticide consumption is met from imports. The main reason is the shift of government's policy to promote domestic production capacity by providing incentives (e.g., waiver of import duties on technical materials and key ingredients). A total of 10 companies are involved in local production of pesticides. Key pesticides formulated in the country are Carbofuran (5\% GR), Diazinon (10\% GR and 60\% EC), Butachlor (5\% GR), Malathion (57\% EC), and Fenitrothion (50\% EC) (Aziz, 2005). The formulation license is issued in accordance with the guidelines of 'Integrated International Safety Guidelines for Pesticide Formulation in Developing Countries' and clearance from the Department of Environment on the emissions record from the production site. Also, quarterly medical check-ups for the workers at the formulation plant are mandatory (Aziz, 2005). 


\subsection{Determinants of pesticide use in Bangladesh}

Table 3 presents the parameter estimates of the system of equations (Eqs. 3and 4) jointly estimated using 3SLS regression procedure. The model diagnostics reveal that the fit is highly satisfactory with nine of the 12 coefficients on the variables being significantly different from zero at $10 \%$ level at least. The Chi-squared values confirm that these variables jointly explain variations in pesticide use as well as GR technology adoption (Table 3, bottom panel).

Results clearly show that the expansion of GR technology is a significant determinant of growth in pesticide use which was also noted in farm-level studies (e.g., Rahman, 2003; Pingali and Rola, 1995). Also, crop diversification (i.e., shifting mainly from cereals to non-cereals) significantly increases pesticide use, which was confirmed by farm-level studies claiming that the production of non-cereals, particularly vegetables, significantly increase pesticide use (e.g., Dasgupta et al., 2005; Mahmud and Shively, 2004; Rahman, 2003; Rahman and Hossain, 2003; Hossain et al., 1999). The average farm size also significantly increases pesticide use, also reported in farm-level studies (e.g., Rahman 2003). Literacy rate also positively influences pesticide use. It is encouraging to see that $R \& D$ investment negatively influence pesticide use. The implication is that new technologies released from the agricultural research stations seems not to be directly pesticide dependent. The role of extension on pesticide use is not significant.

Table 3 also reveals that modern irrigation, crop concentration and R\&D investments significantly increase adoption of GR technology as expected. But average farm size negatively influences GR technology adoption. The implication is that smaller farms tend to adopt GR technology more, perhaps to reap the benefits generated from increased production per unit of land area.

[Insert Table 3 here] 


\section{Pesticide management practices in Bangladesh}

\subsection{Regulatory framework for pesticide use and trade}

In Bangladesh, chemical control has been the primary method for pest management. Until 1974, the government promoted use of pesticides by supplying them free of cost to farmers $(100 \%$ subsidy). The subsidy was then reduced to $50 \%$ in 1974 and was withdrawn completely in 1979 (Matin, 2003). Pesticides are required to be registered by law for sale in the market. A Pesticide Ordinance was promulgated in 1971 to regulate import, manufacture, formulation and distribution of pesticides, and has been subsequently amended in 1980, mainly to accommodate the provision for licensing (Aziz, 2005). A set of rules regarding pesticide use were framed in 1985 to carry out the provision of the Pesticide Ordinance. The Ordinance extends to all pesticides, whether used for agriculture, public health or any other purposes (Aziz, 2005). The Plant Protection Wing of the Ministry of Agriculture (MOA) administers and controls use of pesticides. The Pesticide Technical Advisory Committee, chaired by the Secretary of MOA, finally grants registration to a brand of pesticide after thorough examination of all reports.

A total of 94 types of active ingredients were used for agricultural applications which were marketed through 628 brands in 2005. Another 21 types of active ingredients, marketed by an additional 170 brands, were meant for public health purposes (Table 4). The growth in the number of brands has exploded in recent years. Rahman et al. (1995) reported only 48 brands of pesticides in 1983 increasing to 158 brands in 1989. In a space of another 16 years, the number of brands increased by almost $400 \%$ to 628 brands in 2005 (Table 4). Also, the number of companies engaged in the pesticide business increased by 300\% from only 31 in 1989 (Rahman et al., 1995) to 111 in 2005 (DOE, 2005). Registration of a particular pesticide is valid for three 
years, issued by the Director of Plant Protection of MoA, and must be reapplied at the end of the three years for renewal (Aziz, 2005; Rahman et al., 1995).

\section{[Insert Table 4 here]}

\subsection{Banned pesticides}

Pesticides which do not conform to the regulatory framework are banned. Table 5 lists the names of these banned pesticides. Also, a total of 27 active ingredients and 67 brands were removed from the registration list during mid-1997 due to perceived hazards to human health and the environment (DOE, 2005). The government of Bangladesh is a signatory of the Stockholm Convention on Persistent Organic Pollutants (POPs). Table 6 presents data on the import of POPs to Bangladesh during the period 1955-1997. An estimated 1,521.1 metric tons of POPs were imported during this period, dominated by Chlordane, Dieldrin and Heptachlor. Although, formal import of POPs stopped since mid-1997, banned pesticides, particularly the 12 controversial pesticides (POPs), commonly known as the 'dirty dozen', is still widely available in the market (SOS-Arsenic.net, 2004). Selected farm level surveys also reveal continued use of banned pesticides. For example, a survey of 81 hybrid vegetable seed and cereal producers from 29 villages of north-western Bangladesh in 2000 revealed that $21.9 \%$ and $11.1 \%$ of the farmers used Monochrotophos and Phosphamidon, which were banned pesticides (Rahman and Hossain, 2003).

\section{[Insert Tables 5 and 6 here]}

\section{Concerns regarding pesticide use}

Pesticide use in Bangladesh is increasing rapidly which raises serious concern particularly due to the type of pesticides used and the handling practices leading to unwanted health effects and environmental pollution and the evidence of deaths associated with pesticide use. The overall 
current use rate of $3.13 \mathrm{~kg}$ of active ingredient per ha is almost double than the world average of $2.0 \mathrm{~kg} / \mathrm{ha}$ for the year 2004 (Envirostats, 2007). It is also important to note that the farm-level use rates are similar to the national average estimated in this study, thereby providing consistent evidence of excessive pesticide use in Bangladesh. For example, farm-level average pesticide use rate over a crop year cycle is estimated at $2.3 \mathrm{~kg}$ and $4.0 \mathrm{~kg}$ of active ingredient per ha by Rahman and Hossain (2003) and Rahman (2003), respectively.

Pesticide overuse is also observed. A study administered by the World Bank concluded that over $47 \%$ of the 821 Bangladeshi farmers surveyed in 2003 are overusing pesticides at a rate of $3.4 \mathrm{~kg}$ per ha per growing season (Dasgupta et al., 2005). They have also noted that the health effects reported by these farmers are directly related to the amount of pesticides they have used in crop cultivation (Dasgupta et al., 2005).

The number of applications of pesticides by farmers is another source of concern. The number of pesticide applications per season varies between 1 to 16 times (average 4 applications) (Dasgupta et al., 2005) and 1 to 10 times (average 4.4 applications), respectively (Rahman and Hossain, 2003). Furthermore, Bangladeshi farmers are still using banned pesticides (Rahman and Hossain, 2003).

Another major concern is the lack of awareness of the harmful effects of pesticides, as well as safe handling practices by farmers. For example, although $49 \%$ of the 821 surveyed farmers reported frequent health symptoms associated with pesticide poisoning, only $4 \%$ reported that they were formally trained in pesticide use and $87 \%$ openly admitted to using little or no protective measures while applying pesticides (Dasgupta et al., 2005). Similarly, only 44\% of the 81 surveyed farmers reported use of hand-made face masks while applying pesticides which do not meet the required safety standards (Rahman and Hossain, 2003). 
Apart from the health impacts of the farmers, impact on the environment is also a concern. There is evidence of the off-site effect of pesticide use in the environment, as $11 \%$ of tested water samples contained pesticide residues at levels higher than the WHO guidelines (Government of Bangladesh, 1995b cited in Mahmoud and Shively, 2004). Matin (2003) noted detection of residues of organochlorines, DDT and its metabolites in water, sediment and fish muscle samples collected from various sources during 1992-1995.

An increase in the availability of several brands of pesticide in the market reflects government's preference to use chemicals to control pests. Nevertheless, the availability of a huge number of active ingredients of pesticides marketed through several hundred brands coupled with misleading advertisements will confuse the farmers who are largely illiterate. Studies documented that pesticides are widely over- or misused in Bangladesh due to inadequate labelling and lack of farmer knowledge (Ramaswamy, 1992; Jackson, 1991 cited in Mahmoud and Shively, 2004) as observed elsewhere, such as, India and China (Abhilash, 2009; Brauw et al., 2000 cited in Hou and $\mathrm{Wu}, 2010$ ). Dasgupta et al., (2005) reported that the farmers used a total of 161 formulations (including 50 different active ingredients) of which $19 \%$ were extremely hazardous (WHO class I), 51\% very hazardous (WHO class II), 10\% moderately hazardous (WHO class III) and only 20\% were low risk (WHO class U).

\section{Integrated pest management in Bangladesh: A way forward?}

Bangladesh officially launched a national Integrated Pest Management (IPM) Policy in January 2002 based on the realization that: (a) crop production needs to be sustained; (b) pests continue to cause serious damage to crops, and (c) the use of chemical control methods will seriously affect human health and the environment (MOA, 2002). The main components of IPM policy 
are: (i) maintaining ecological balance; (ii) executing appropriate actions on pesticides; (iii) operating an effective system for implementing the national IPM program; (iv) developing human resources as the core of IPM; and (v) conducting research on IPM (MOA, 2002).

IPM first started in Bangladesh in 1981 through FAO inter-country programme (ICP) primarily targeting rice crop. Later IPM expansion gained momentum from the 1990s through a number of long-term projects largely funded by FAO, CARE, DANIDA, UNDP, and USAID (Rahman, 2009a).

In order to build capacity of the farmers, Farmers Field Schools (FFS) were introduced since the early 1990s to train them in the use of IPM technologies which are now fairly established (Rahman, 2009a). Starting from only a total of 1,137 officials from the DAE, 300 staff from the different NGOs, and 829 farmers trained as IPM trainers during early 2000, about 875,000 farmers or some $7.4 \%$ of the 11.8 million farming families in Bangladesh are currently benefitting from IPM-FFS training (FAO, 2011; MOA, 2002).

Existing literature demonstrates that the impact of IPM-FFS on farmers has been generally positive and far reaching. Van den Berg and Jiggins (2007), in their assessment of the impact of FFS, identified two significant areas of impact: (i) immediate reduction in pesticide use and in many cases a substantial yield increment in Asia; and (ii) triggering further development beyond IPM in the field of experimentation, collective action, leadership, planning and organization. Tripp et al., (2005) also noted that the experience of FFS in reducing insecticide use is positive in Sri Lanka. In Bangladesh, success of IPM includes a reduction of pesticide use by $90 \%$ and $75 \%$ while subsequently raising crop yields by $10 \%$ and $12 \%$ by rice and aubergine farmers, respectively (FAO, 2011). Also, proper use of IPM practices can reduce 
the cost of pesticides in vegetables (e.g., aubergine, gourd and cucumber) by BDT 7,500-16,000 per ha (i.e., USD 108-232) (Katalyst, 2010).

\section{Conclusions and Policy Implications}

Bangladesh, overwhelmingly an agricultural economy, has followed the path of rapid diffusion of a rice-based GR technology over the past four decades in order to attain the goal of selfsufficiency in foodgrains (Rahman, 2010). Also, the government has emphasized crop diversification since the early 2000 s in order to promote agricultural growth and export earnings (Rahman, 2009). Both these policy driven factors has resulted in a significant increase in the use of pesticides as demonstrated in this study. The results also revealed that the productivity of pesticide use has been falling significantly over time which raises serious concerns on sustaining growth in agriculture through increased use of pesticides as the principal means to control pests.

During the initial years, chemical methods of pest control were the primary focus of the government to increase crop production and prevent pre- and post-harvest crop losses. However, the government later realized the need to embark on IPM technologies in order to reduce the impacts of pesticides on farmers' health and the environment. Even though the regulatory practices of pesticide use seem quite well defined on paper, strict enforcement of regulations has been rather weak and there is considerable evidence to suggest widespread use of banned pesticides in the country even today. Use of IPM initiated three decades ago in 1981 subsequently backed up by a national IPM Policy in 2002 has been rather slow in its coverage as it has only reached an estimated $7.4 \%$ of the total farming families so far.

Although, in principle, the goal of the government should be to adopt a more sustainable practice of pest control in the long-run, Bangladesh needs a combined and focused approach to 
combat the explosion in pesticide usage observed at present. The three broad areas of intervention that need attention are: (i) strict enforcement of existing pesticide regulations (e.g., identification of suppliers of banned pesticides instead of superficially managing through licensing control) and registration of pesticide products with limits placed on its use including guidelines to describe the proper manner of application; (ii) raising mass awareness of the harmful effects of pesticide use and the importance of safe pesticide handling and management practices (e.g., through existing agricultural extension networks, mass media as well as the NGOs); and (iii) an expansion of IPM technologies (e.g., through targeted public, private businesses and local NGO initiatives). Van den Berg and Jiggins (2007) noted that institutionalization of FFS programmes, both at the national and local level, through targeted investment and adding value through support to farmer driven initiatives could be a desired strategy. However, they also emphasized that to sustain FFS programs, a clearly defined policy environment is needed which effectively exerts tighter control on chemical pesticides and addresses the specific needs of the farmers as well. 


\section{REFERENCES}

Antle, J.M., Pingali, P.L., 1994. Pesticides, productivity and farmer health: a Philippine case study. American Journal of Agricultural Economics, 76, 418-430.

Aziz, M.A., 2005. Bangladesh Country Paper. Proceedings of the Regional Workshop on Implementation Monitoring and Observance: International Code of Conduct on the Distribution and Use of Pesticides. FAO-RAPA, Thailand. Available at: http://www.fao.org/docrep/008/af340e/af340e00.HTM

BBS, (various issues). Statistical Yearbook of Bangladesh, 1980 to 2010. Bangladesh Bureau of Statistics, Dhaka.

BBSa, 2009. Handbook of Agricultural Statistics, 2007. Bangladesh Bureau of Statistics, Dhaka.

BBSb, (various issues). Bangladesh Census of Agriculture and Livestock, 1983/84, 1996 and 2008. Bangladesh Bureau of Statistics, Dhaka.

BBSc, (various issues). Bangladesh Population Census, 1981, 1991, 2001 and 2011. Bangladesh Bureau of Statistics, Dhaka.

Carvalho, F.P. 2006. Agriculture, pesticides, food security and food safety. Environmental Science and Policy, 9: 685-692.

Damalas, C.A., Eleftherohorinos, I.G. 2011. Pesticide exposure, safety issues, and risk assessment indicators. International Journal of Environmental Research and Public Health, 8: 1402-1419.

Das, G.P. 1998. Major insect and mite pests of important crops and stored products of Bangladesh. Bangladesh Agricultural Research Institute, Gazipur-1701.

Dasgupta, S., Meisner, C., Huq, M., 2005. Health effects and pesticide perception as determinants of pesticide use: evidence from Bangladesh. World Bank Policy Research 
Working Paper \#3776. Washington, D.C.

DOE, 2005. Bangladesh: Preparation of POPs National Implementation Plan under Stockholm Convention. First Draft Report: Field data collection and preparing inventories on use/stock/produces/sources of POPs pesticides in Bangladesh. Government of Bangladesh. Available at: http://www.sdnpbd.org/sdi/issues/environment/document/pesticide_inventory_1_draft.pdf Envirostats, 2007. Environmental Statistics and other topics to think about. A dedicated website available at: http://envirostats.info/2007/09/16/0398/

FAO, 2011. Bangladesh and FAO achievements and success stories. Rome, Italy. Available at: http://www.fao.org/fileadmin/templates/rap/files/epublications/BangladeshedocFINAL.p $\underline{\mathrm{df}}$

Hossain, M.I., Shively, G., Mahmoud, C., 1999. Factors influencing pesticide use in ricevegetable farming system in Bangladesh. Bangladesh Journal of Agricultural Economics, 22, 87-98.

Hou, B., Wu, L. 2010. Safety impact and farmer awareness of pesticide residues. Food and Agricultural Immunology, 21: 191-200.

IRIN, 2010. Bangladesh: pesticide poisoning takes its toll. IRIN news, Jan 18, 2010. Available @ http://www.irinnews.org/Report/87773/BANGLADESH-Pesticide-poisoning-takesits-toll.

Katalyst, 2010. Prospects of Integrated Pest Management in Bangladesh. News Issue, 14, March 02, 2010. Available at: http://www.katalyst.com.bd/docs/newspieces/News_Issue_14.pdf

Mahmoud, C., Shively, G., 2004. Agricultural diversification and integrated pest management in Bangladesh. Agricultural Economics, 30, 187-194. 
Matin, M.A. Pesticides in Bangladesh. In Taylor, M.D., Klaine, S.J. Carvalho, F.P., Barcelo, D., and Everaarts, J., (Eds.) Pesticide Residues in Coastal Tropical Ecosystems: Distribution, Fate and Effects. pp: 137-158. Taylor and Francis Group, London.

MOA, 2002. National Integrated Pest Management Policy. Ministry of Agriculture, Government of Bangladesh.

Nhan, D.D. 2003. Distribution, fate, and impact of pesticides in the tropical marine environment of Vietnam. In Taylor, M.D., Klaine, S.J. Carvalho, F.P., Barcelo, D., and Everaarts, J., (Eds.) Pesticide Residues in Coastal Tropical Ecosystems: Distribution, Fate and Effects. pp: 180-219. Taylor and Francis Group, London.

Pimentel, D., 2005. Environmental and socio economic costs of the applications of pesticides primarily in the United States. Environment, Development and Sustainability, 7, 229252.

Pingali, P.L., 1995. Impact of pesticides on farmer health and the rice environment: an overview of results from a multidisciplinary study in the Philippines. In: Pingali, P.L., Roger, P. (Eds.), Impact of Pesticides on Farmer Health and the Rice Environment. Kluwer Academic Publishers, Boston.

Pingali, P.L., Rola, A.C., 1995. Public regulatory roles in developing markets: the case of Philippines. In: Pingali, P.L., Roger, P. (Eds.), Impact of Pesticides on Farmer Health and the Rice Environment. Kluwer Academic Publishers, Boston.

PC (various issues). Annual/Revised Annual Development Reports, 1977 to 2010. Planning Commission, Dhaka, Bangladesh.

Raghu, K., Pandit, G.G., Murthy, N.B.K., Rao, A.M.M., Mukherjee, P.K., Kale, S.P., Mitra, J. 2003. Distribution, fate and effects of pesticides in the tropical coastal zones of India. In 
Taylor, M.D., Klaine, S.J. Carvalho, F.P., Barcelo, D., and Everaarts, J., (Eds) Pesticide Residues in Coastal Tropical Ecosystems: Distribution, Fate and Effects. pp: 81-136. Taylor and Francis Group, London.

Rahman, M.M. 2009a. Vegetable IPM in Bangladesh. In Radcliffe's IPM World Text Book, University of Minnesota, USA. Available @ http://ipmworld.umn.edu/ipmchap.htm

Rahman, M.S., Malek, M.A., Matin, M.A., 1995. Trend of pesticide usage in Bangladesh. The Science of the Total Environment, 159, 33-39.

Rahman, S. 2010. Six decades of agricultural land use change in Bangladesh: Effects on crop diversity, productivity, food availability and the environment, 1948-2006. Singapore Journal of Tropical Geography, 31, 254-269.

Rahman, S. 2009. Whether crop diversification is a desired strategy for agricultural growth in Bangladesh". Food Policy, 34, 340-349.

Rahman, S., 2003. Farm-level pesticide use in Bangladesh: determinants and awareness. Agriculture, Ecosystems and Environment, 95, 241-252.

Rahman, S., Hossain, M.Z., 2003. Pesticide demand in hybrid seed production technology. Journal of Food, Agriculture and Environment, 1, 174-179.

SOS-Arsenic.net, 2004. Agrochemicals: imported pollutants in Bangladesh. Available at http://www.sos-arsenic.net/index.html.

STATA, (2007) STATA Statistical Software Release 10.0. College Station, TX: Stata Corporation.

Tripp, R., Wijeratne, M., Piyadasha, V.H., 2005. What should we expect from Farmer Field Schools? A Sri Lanka case study. World Development, 33, 1705-1720.

Van den Berg, H., Jiggins, J., 2007. Investing in farmers - the impacts of Farmer Field Schools 
in Relation to Integrated Pest Management. World Development, 35, 663-686.

Wilson, C., Tisdell, C., 2001. Why farmers continue to use pesticides despite environmental, health and sustainability costs? Ecological Economics, 39, 449-462.

World Bank.org, undated. Toxic pollution from agriculture: an emerging story. Available at http://econ.worldbank.org/research/toxic pollutin ...html. 


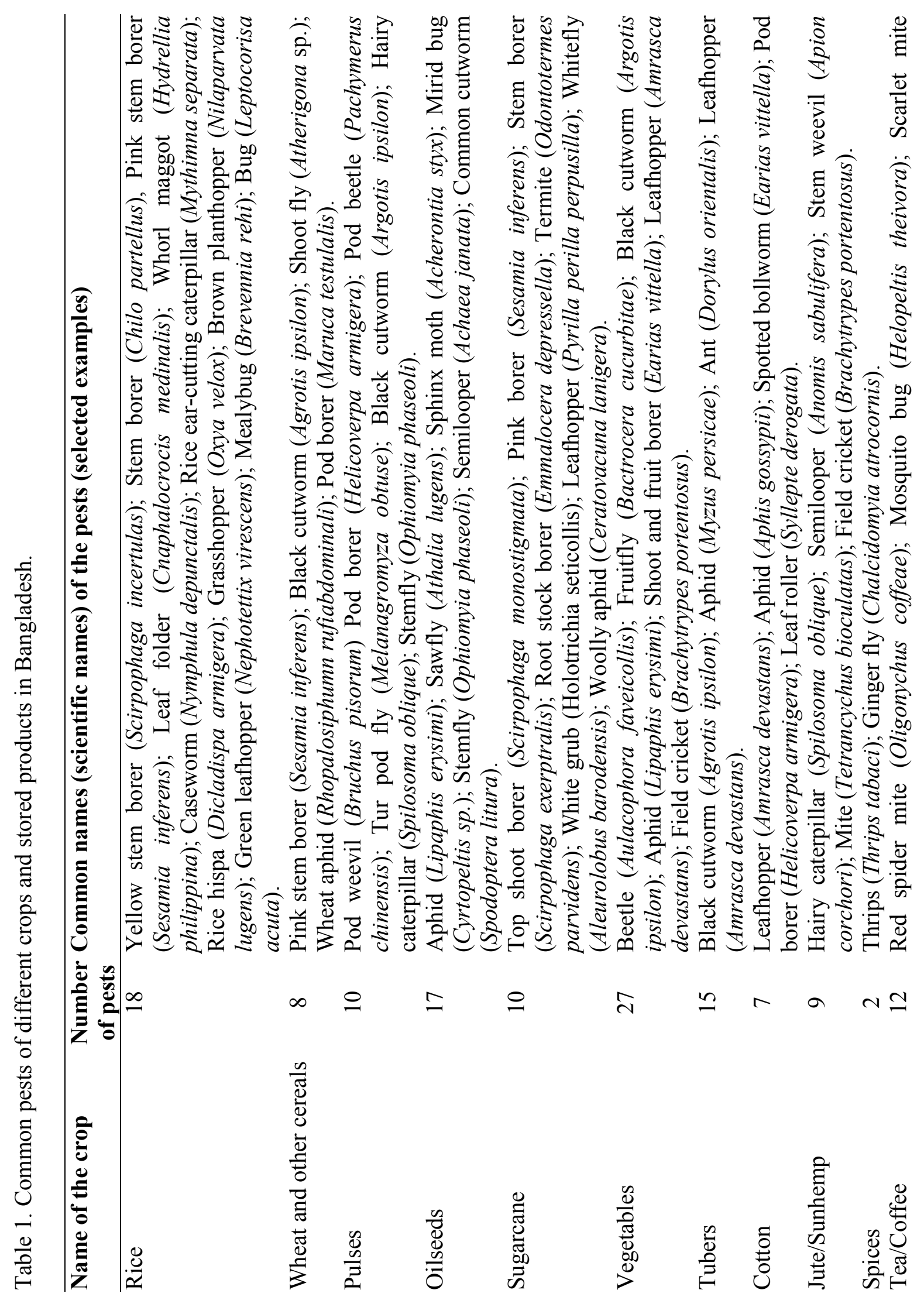




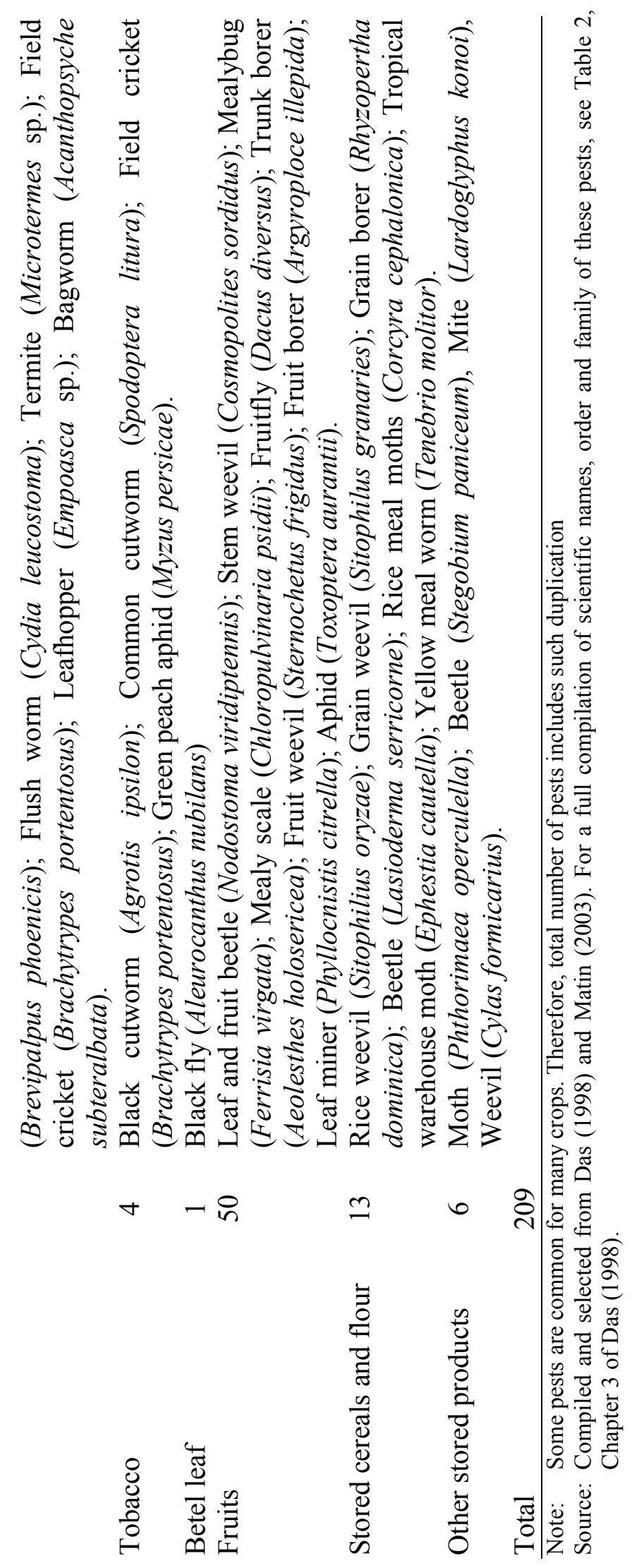


Table 2. Growth rate estimates of pesticides, fertilizers and selected major crops (1977-2009).

\begin{tabular}{|c|c|c|c|}
\hline & Variables & Averages (1977-2009) & $\begin{array}{r}\text { Average annual } \\
\text { compound growth rates } \\
(1977-2009)\end{array}$ \\
\hline \multirow[t]{7}{*}{$\mathbf{A}$} & Trends in cropped area & Share in GCA (\%) & \\
\hline & HYV rice & 34.53 & $0.054 * * *$ \\
\hline & Wheat & 4.14 & $0.017 * * *$ \\
\hline & Pulses & 3.88 & -0.004 \\
\hline & Oilseeds & 3.17 & 0.000 \\
\hline & Spices & 1.35 & $0.023 * * *$ \\
\hline & Potatoes & 1.58 & $0.026 * * *$ \\
\hline \multirow[t]{3}{*}{$\mathbf{B}$} & Trends in pesticide and fertilizer use & & \\
\hline & Fertilizer nutrients & & $0.057 * * *$ \\
\hline & Pesticides (active ingredients) & & $0.100 * * *$ \\
\hline \multirow[t]{7}{*}{ C } & Trends in crop productivity & Yield (mt/ha) & \\
\hline & HYV rice yield & 2.50 & $0.010 * * *$ \\
\hline & Wheat yield & 1.94 & 0.003 \\
\hline & Pulses yield & 0.71 & $0.008 * * *$ \\
\hline & Oilseeds yield & 1.02 & $0.020 * * *$ \\
\hline & Spices yield & 2.30 & $0.016 * * *$ \\
\hline & Potatoes yield & 11.38 & $0.013 * * *$ \\
\hline \multirow[t]{3}{*}{$\mathbf{D}$} & $\begin{array}{l}\text { Trends in pesticide and fertilizer use } \\
\text { rate }\end{array}$ & Use rate (kg/ha of GCA) & \\
\hline & Fertilizer use rate & 72.60 & $0.056 * * *$ \\
\hline & Pesticide use rate & 0.80 & $0.101 * * *$ \\
\hline \multirow[t]{3}{*}{$\mathbf{E}$} & $\begin{array}{l}\text { Trends in pesticide and fertilizer } \\
\text { productivity }\end{array}$ & Productivity (BDT/kg) & \\
\hline & Fertilizer productivity & 185.30 & $-0.042 * * *$ \\
\hline & Pesticide productivity & $25,073.60$ & $-0.086 * * *$ \\
\hline
\end{tabular}


Table 3. Determinants of pesticide use in Bangladesh.

\begin{tabular}{lcrrr}
\hline Variables & \multicolumn{3}{c}{ Joint estimation of pesticide use and GR technology adoption } \\
& \multicolumn{2}{c}{$\begin{array}{r}\text { Pesticide use rate model } \\
\text { models using 3SLS procedure } \\
\text { GR adoption rate model }\end{array}$} \\
\cline { 2 - 5 } Coefficients & t-ratio & Coefficients & t-ratio \\
\hline Constant & $15.5221^{*}$ & 1.65 & -0.8808 & -1.43 \\
Endogenous variable & & & & \\
GR adoption rate & $11.6160^{* *}$ & 2.32 & -- & -- \\
Exogenous variables & & & & \\
Irrigation rate & -- & -- & $0.2501 * * *$ & 2.63 \\
Crop diversification & $-13.8201^{* *}$ & -1.97 & $1.0370^{* * *}$ & 4.97 \\
R\&D investment & $-2.5248^{*}$ & -1.91 & $0.1958^{* * *}$ & 3.97 \\
Extension expenditure & 0.1572 & 0.59 & -0.0172 & -0.97 \\
Average farm size & $32.1794^{* *}$ & 2.14 & $-2.4931^{* * *}$ & -6.33 \\
Literacy rate & $4.2302^{* *}$ & 2.00 & -0.2399 & -1.36 \\
Model diagnostics & & & & \\
$\mathrm{R}^{2}$ from OLS regressions & 0.74 & & 0.99 & \\
Chi-squared & $123.73^{* * *}$ & & $5850.27 * * *$ & 33 \\
Number of observations & 33 & &
\end{tabular}

Note: $\quad * * *=$ significant at $1 \%$ level $(\mathrm{p}<0.01)$

$* *=$ significant at $5 \%$ level $(\mathrm{p}<0.05)$

$*=$ significant at $10 \%$ level $(\mathrm{p}<0.10)$ 
Table 4. Number of active ingredients and marketed brands of pesticides

\begin{tabular}{lcr}
\hline Type and purpose & Number of active ingredients & Number of brands \\
\hline For agricultural use & & \\
Insecticides & 43 & 401 \\
Fungicides & 23 & 81 \\
Acaricides & 09 & 53 \\
Herbicides & 13 & 78 \\
Rodenticides & 06 & 15 \\
\hline Total & 94 & 628 \\
\hline For public health use & & 170 \\
Insecticides & 21 & \\
Source: Adapted from Aziz (2005) & &
\end{tabular}


Table 5. List of banned pesticides

\begin{tabular}{llr}
\hline Type & Common name & Number of brands \\
\hline POPs & Chlordane & 1 \\
& Dieldrin & 4 \\
& Heptachlor & 1 \\
Non-POPs & CCA & 2 \\
& DDVP & 4 \\
& Dichlorovos & 7 \\
& Dicrotophos & 2 \\
& Methyl Bromide & 4 \\
& Monocrotophos & 14 \\
& Phosphamidon & 2 \\
\hline Source: Compiled from
\end{tabular}


Table 6. Import of POP pesticides, 1955-1997

\begin{tabular}{|c|c|c|c|c|}
\hline POP pesticides & 1955-1965 & 1960-1974 & 1974-1985 & 1986-1997 \\
\hline Endrin & 25.00 & & & \\
\hline BHC & 94.72 & & & \\
\hline DDT & 66.69 & & & \\
\hline Aldrin & 70.00 & & & \\
\hline Chlordane & & 30.80 & 2.20 & NA \\
\hline Dieldrin & & 227.33 & 194.85 & 56.52 \\
\hline Heptachlor & & 186.73 & 160.05 & 406.18 \\
\hline Total (metric tons) & 256.41 & 444.86 & 357.10 & 462.70 \\
\hline
\end{tabular}




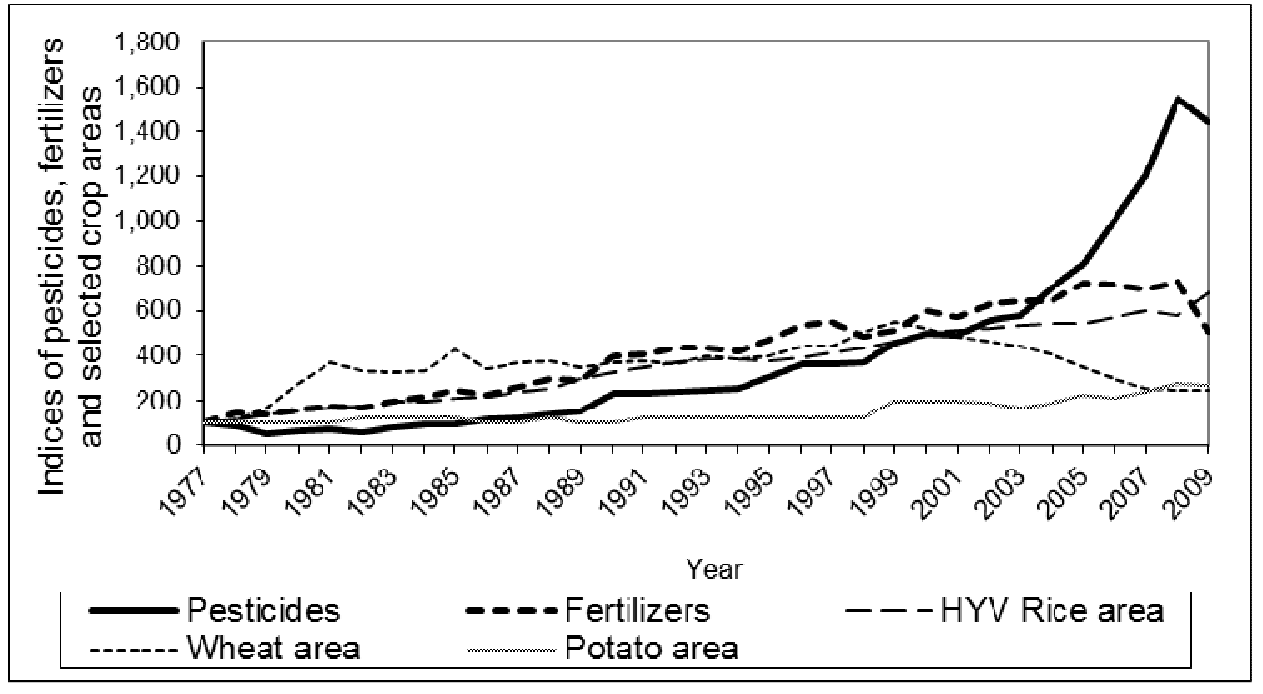

Figure 1. Growth in pesticide and fertilizer consumption as well as land area under major crops. 


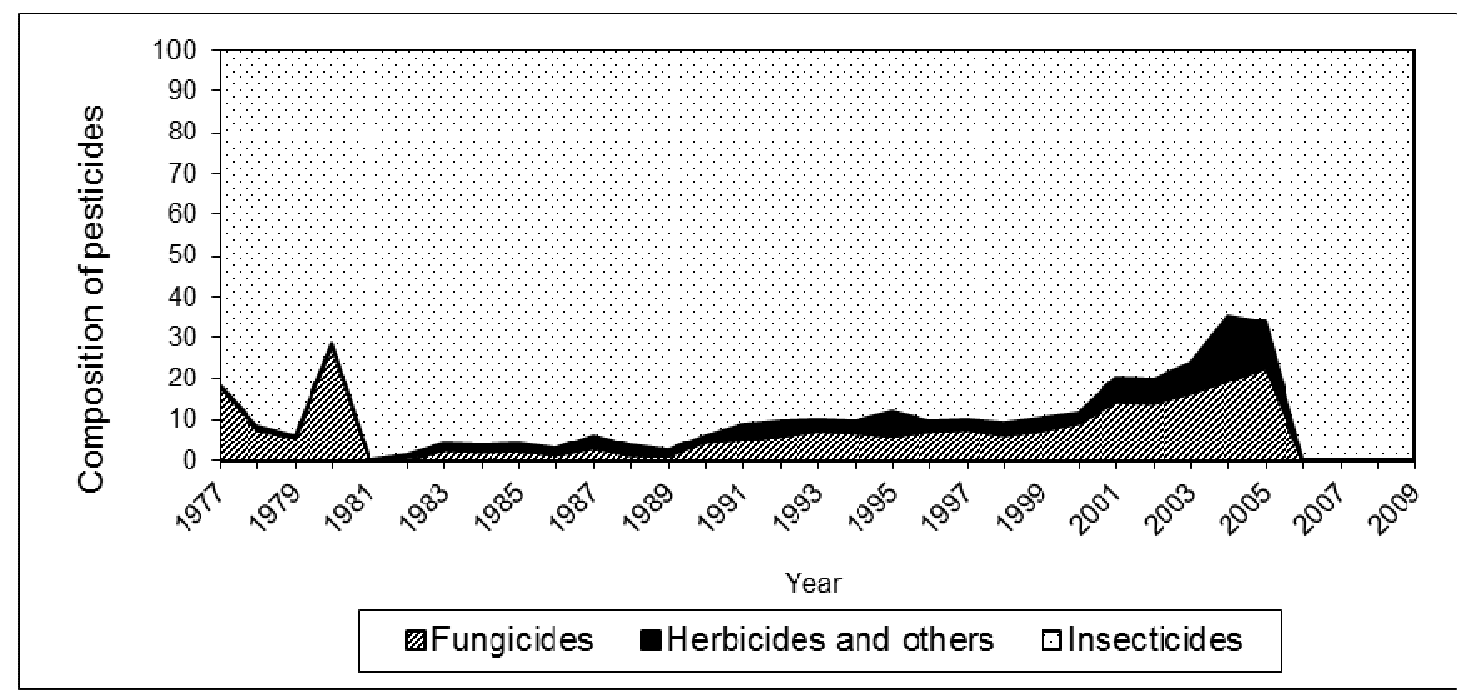

Figure 2. Composition of pesticides. 


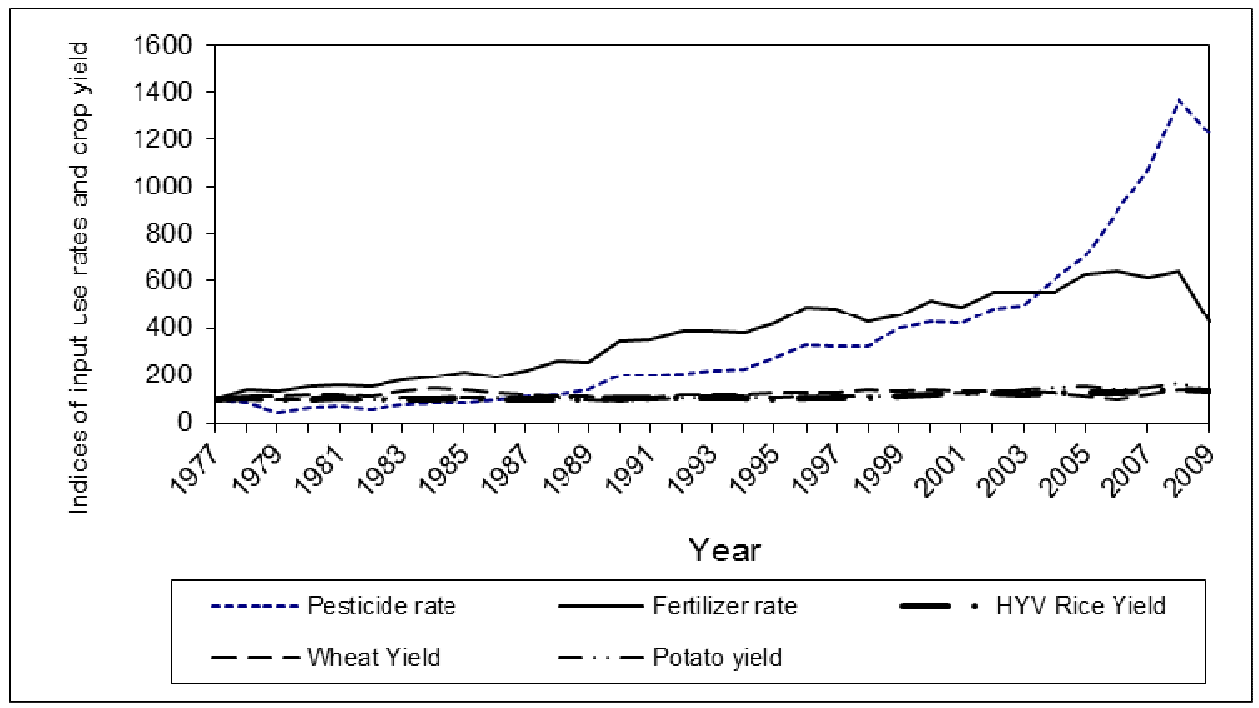

Figure 3. Growth in the use rates of pesticides and fertilizers per hectare of gross cropped area as well as yield of major crops per ha. 


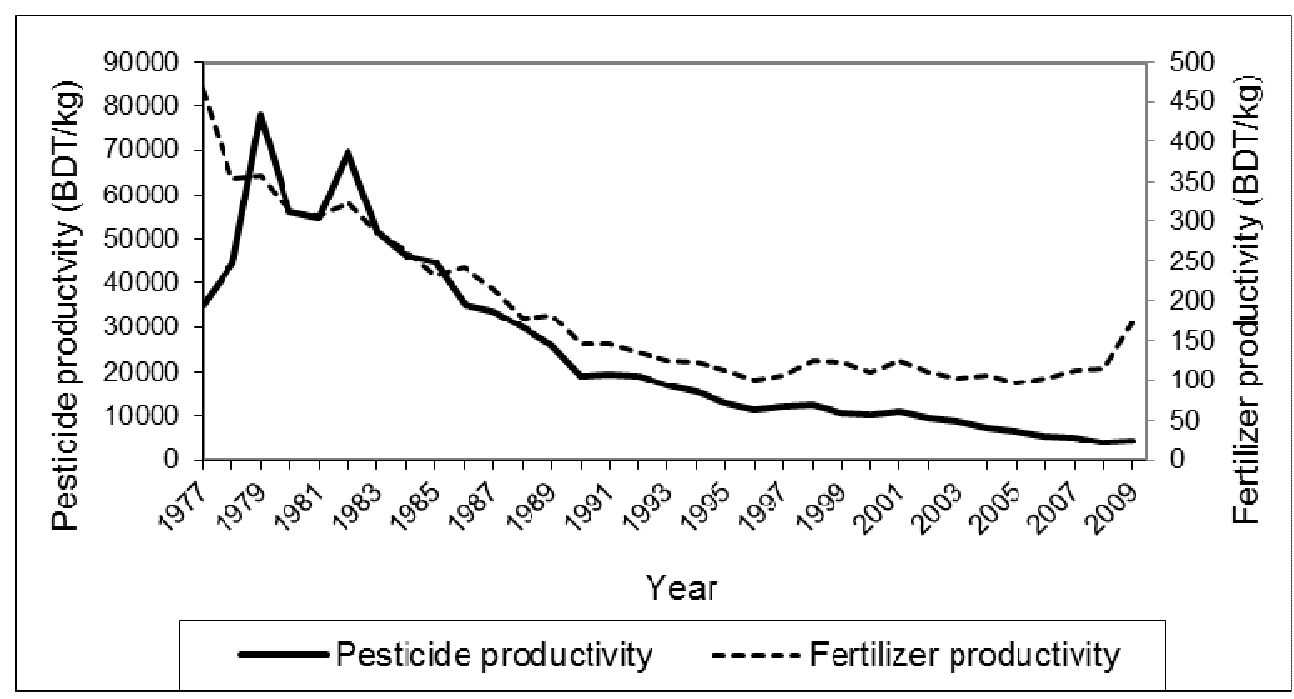

Figure 4. Trends in pesticide productivity and fertilizer productivity. 